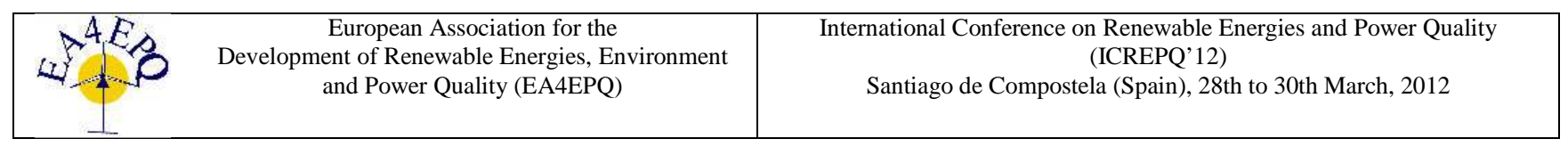

\title{
Biogas Production Potential from Reeds
}

\author{
Vilis Dubrovskis, Valters Kazulis \\ ${ }^{1}$ Latvia University of Agriculture, Jelgava, Phone +371 26410882, Fax +37126410882 , \\ vilisd@inbox.lv
}

\begin{abstract}
Aim of this research was to study the use of reeds for biogas production. Reeds from the Pape lake area were selected for anaerobic digestion experiments in laboratory. Reeds were chopped and prepared in four groups from $1 \mathrm{~mm}$ up to $20 \mathrm{~mm}$. Their chemical and physical properties were analyzed. The results show more methane can be extracted from green reeds $0,281 \mathrm{lCH} / \mathrm{gDOMadd}$ and from dry reeds 0,226 $1 \mathrm{CH} 4 / \mathrm{gDOMadd}$ - the smaller reeds were chopped the greater methane yield. Experiment results show reeds are more useful in biogas production when in cofermentation with other raw materials. Profitable biogas extraction from reeds can be accomplished in adjunction with sapropel and fertilizer production.
\end{abstract}

\section{Key words}

reeds, biogas, methane, anaerobic digestion

\section{Introduction}

The first purpose for biogas production plant is manure treatment for environment advantages, and the second purpose is meeting growing energy demands in a situation when cost of fuel and energy is increasing rapidly. Over the past decade there have been considerable efforts in the development of biogas production technologies in many EU countries [1].

Energy from biomass is considered to have an outstanding role in Europe's energy policy. The main objective of the Biomass Action Plan was to provide $8 \%$ of Europe's energy demand from biomass in year 2010, prevent greenhouse gas emissions worth 209 million tons $\mathrm{CO}_{2}$ equivalent per year and create up to 300000 new jobs in the agriculture and forestry sector. Biogas sector in some

Table1. Power of Electricity Production from Biogas in Latvia, MWel
European countries is currently facing rapid technical and non-technical developments and innovations. Biogas market is growing at considerable pace.

Biogas production ensuring methane collection helps fulfilling Latvia's international obligations for implementation of Kyoto Protocol requirements. According to EC directives the renewable energy share in gross energy consumption should increase from $32.5 \%$ in 2005 up to $40 \%$ in 2020 for Latvia [1]. Latvia's renewable energy share in gross energy consumption was only $29.9 \%$ in 2008; therefore new alternative energy resources should be utilized to reach the appointed targets in the energy sector.

Latvia has more than 369000 ha land that can be used for growing energy crops. Previous approximate consideration showed possibility of building biogas plants with total electricity output of more than $300 \mathrm{MWel}$. In Latvia activities for rapid development of biogas technologies started only some years ago after government support increased feed-in tariff. Building of 58 biogas plants has been planned for this year. Quota for selling electricity to the grid is shown in Table 1.

Additional renewable energy supply can be provided by increasing the area of intensive energy crops providing high dry matter (DM) yields [2]. Energy crops used for biogas production should provide high dry matter yield and high methane output per area unit. Energy crops should be easy to cultivate, i.e., to be tolerant to weeds, pests, diseases, drought and frost, have good winter hardiness and be able to grow with low nutrient input.

\begin{tabular}{|l|l|l|l|l|l|}
\hline Years & $2001-2009$ & 2010.1 .10 & Forecast 2011 & Quota 2011MWh & $\begin{array}{l}\text { 2020 according to } \\
\text { the Action Plan }\end{array}$ \\
\hline Landfills & 6.11 & 6.11 & 6.11 & & \\
\hline Sewage & 2.096 & 2.096 & 2.096 & & \\
\hline
\end{tabular}




\begin{tabular}{|l|l|l|l|l|l|}
\hline Agriculture & 0.26 & 1.76 & 62.25 & & \\
\hline Silage & & & 2.5 & & \\
\hline Total & 8.466 & 10.37 & 72.96 & 467,959 & 92 \\
\hline
\end{tabular}

\section{Research}

\section{A. Materials \& Preparation}

Reeds growing in the Pape lake area were selected for the research. Half of reeds for experiments were mowed during the cold period when they had already dried, other half were mowed in June and consisted of green reeds that had not yet reached the flowering stage. Stalks and leaves were grounded using LUA grinding equipment and sieved through appropriate sieves. Reeds mowed in the cold period were dry crushed in following groups: 1) Up to $1 \mathrm{~mm}$;

2) Up to $2 \mathrm{~mm}$;

3) Up to $5 \mathrm{~mm}$;

4) Up to $20 \mathrm{~mm}$

Reeds mowed in June were grinded into groups of:

1) up to $2 \mathrm{~mm}$;

2) up to $5 \mathrm{~mm}$;

3) up to $7 \mathrm{~mm}$;

4) up to $20 \mathrm{~mm}$.

Following standardized methodologies of ISO chemical compositions of reed samples were determined in LUA Agro biotechnology laboratory and are illustrated in table 2. Additional analysis of elements, illustrated in table 3 , was carried out using the equipment of bioenergy laboratory. The amount of total solids, volatile organic solids, ash and element content were determined analyzing samples of each raw material group and yeast. Analysis was performed following the standard methods. Amounts of total solids were determined heating samples at $120^{\circ} \mathrm{C}$. Weights of raw materials and yeast were measured on KERN FKB scales.

The procedures for dry and green reeds were identical. The yeast (culture) for all 16 experiments was taken from plugflow anaerobic digester. 500 grams inoculum and 20 grams grinded reeds were put in 0.7 litre bioreactors (weight accuracy 0.2 grams). Gas collection bags were connected to the 16 bioreactors which were then put in the incubator at $38^{\circ} \mathrm{C}\left( \pm 0.5^{\circ} \mathrm{C}\right)$ and this temperature held constant during the time of experiments. Gas quantity and quality was measured every 24 hours. Every day reactors were agitated to reduce the floating layer.

\section{B. Equipment}

Total solids were determined heating samples in Shimadzu MOC $-120 \mathrm{H}$ analyser. Organic solids were determined heating samples in a specific setting in Nabetherm muffle furnace. Bioreactors were made modifying standard receptacles. Memmert incubators ensured that bioreactors are constant temperature.

Gas quality was measured using Geotech GA2000 Plus gas analyser. Methane, carbon dioxide, oxygen and hydrogen sulphide content was recorded. Weight of raw materials and yeast was measured on KERN FKB scales; pH was measured using meter PP-50.

\section{Methods \& Work Description}

Experiments were carried out periodically during the analysis of released biogas determining methane $\left(\mathrm{CH}_{4}\right)$, carbon dioxide $\left(\mathrm{CO}_{2}\right)$, oxygen $\left(\mathrm{O}_{2}\right)$, and hydrogen sulfide $\left(\mathrm{H}_{2} \mathrm{~S}\right)$ concentration of the reactor gas through a specialized isolates of manufactured and certified instrument "GA2000 Plus".

Pressure was measured and then volume of gas in normal conditions calculated. Total biogas yield was calculated summarizing daily biogas yields and further calculations were done to find the overall methane yield. Results for litres per g organic dry matter added in digester were found. Results are shown in Figure 1 for dry reeds.

\section{Results and Discussion}

Reed Chemical analysis is shown in the Table 2. Compared with agricultural crops, it is evident reeds are high in lignin, cellulose and hemicellulose content. The largest was for less crushed reeds. Compared to data available in other publications, cellulose and hemicellulose content is close to the data available on Estonian lakes [5], but the Pape lake area reeds are significantly higher in lignin content. Reeds from Pape lake area also contain distinctly less $\mathrm{N}$ and $\mathrm{P}$ than the majority of reeds growing in lakes of Estonia. Their contents are shown in Table 3 . Table 4 shows the analysis of dry reeds, and the results from green reeds are available in Table 5.

Table2. Chemical Analysis of Reeds

\begin{tabular}{|l|l|l|l|l|l|}
\hline Name & $\begin{array}{l}\text { Reed } \\
1 \mathrm{~mm}\end{array}$ & $\begin{array}{l}\text { Reed } \\
2 \mathrm{~mm}\end{array}$ & $\begin{array}{l}\text { Reed- } \\
10 \mathrm{~mm}\end{array}$ & $\begin{array}{l}\text { Digestate } \\
\text { fresh mass }\end{array}$ & $\begin{array}{l}\text { Digestate } \\
\mathrm{DM}\end{array}$ \\
\hline $\mathrm{Mg} \%$ & 0,04 & 0,03 & 0,02 & 0,04 & 1,00 \\
\hline $\mathrm{Ca} \%$ & 1,08 & 0,05 & 0,04 & 0,08 & 2,12 \\
\hline $\mathrm{K} \%$ & 0,05 & 0,02 & 0,02 & 0,04 & 0,12 \\
\hline $\mathrm{N} \%$ & 0,46 & 0,24 & 0,29 & 0,01 & 0,12 \\
\hline P\% & 0,03 & 0,02 & 0,01 & 0,03 & 0,71 \\
\hline Lignin\% & 8,13 & 11,78 & 12,22 & 1,55 & 1,97 \\
\hline Cellulose\% & 32,45 & 38,29 & 37,98 & 0,24 & 28,31 \\
\hline Hemicelluloses & 32,16 & 29,88 & 30,17 & 0,52 & 12,70 \\
\hline
\end{tabular}

Table 3. Elemental Composition of Dry and Green Reeds \% DM 


\begin{tabular}{|l|l|l|}
\hline Name of element & Dry reed & Green reed \\
\hline $\mathbf{C}$ & $46,2-47,3$ & $46,9-47,2$ \\
\hline $\mathrm{H}$ & $5,4-5,5$ & $5,87-6,38$ \\
\hline $\mathbf{N}$ & $0,36-0,42$ & $0,64-1,21$ \\
\hline $\mathrm{S}$ & $0,04-0,08$ & $0,07-0,28$ \\
\hline
\end{tabular}

Table 4. Analysis for Variously Chopped Dry Reeds

\begin{tabular}{|c|c|c|c|c|c|c|}
\hline $\begin{array}{l}\text { Chopped } \\
\text { dry reed }\end{array}$ & $\mathrm{pH}$ & $\begin{array}{l}\text { DM } \\
\text { reed }\end{array}$ & $\% \begin{array}{l}\text { ODM \% } \\
\text { reed }\end{array}$ & $\begin{array}{l}\text { Total } \\
\text { weight } \mathrm{g}\end{array}$ & $\begin{array}{l}\text { Total } \\
\text { ODM } \\
\text { reed }\end{array}$ & $\begin{array}{ll}\text { Ash } & \% \\
\text { greed } & \end{array}$ \\
\hline $1 \mathrm{~mm}$ & & 92,65 & 95,6 & 479,0 & 29,98 & 4,4 \\
\hline$-1 \mathrm{~mm}$ & & 92,65 & 95,6 & 478,8 & 29,96 & 4,4 \\
\hline $1 \mathrm{~mm}$ & & 92,65 & 95,6 & 489,8 & 30,17 & 4,4 \\
\hline$-1 \mathrm{~mm}$ & & 92,65 & 95,6 & 490,0 & 30,18 & 4,4 \\
\hline$-2 \mathrm{~mm}$ & & 93,0 & 95,66 & 473,0 & 29,9 & 4,34 \\
\hline$-2 \mathrm{~mm}$ & & 93,0 & 95,66 & 468,2 & 29,77 & 4,34 \\
\hline$-2 \mathrm{~mm}$ & & 93,0 & 95,66 & 480,6 & 30,10 & 4,34 \\
\hline$-2 \mathrm{~mm}$ & & 93,0 & 95,66 & 502,0 & 30,68 & 4,34 \\
\hline$-5 \mathrm{~mm}$ & & 92,96 & 90,15 & 473,4 & 28,88 & 9,85 \\
\hline$-5 \mathrm{~mm}$ & & 92,96 & 90,15 & 464,8 & 28,89 & 9,85 \\
\hline$-5 \mathrm{~mm}$ & & 92,96 & 90,15 & 502,6 & 29,91 & 9,85 \\
\hline$-5 \mathrm{~mm}$ & & 92,96 & 90,15 & 493,0 & 29,64 & 9,85 \\
\hline$-20 \mathrm{~mm}$ & & 90,73 & 97,8 & 489,6 & 29,13 & 2,2 \\
\hline$-20 \mathrm{~mm}$ & & 90,73 & 97,8 & 481,4 & 29,08 & 2,2 \\
\hline$-20 \mathrm{~mm}$ & & 90,73 & 97,8 & 499,8 & 29,58 & 2,2 \\
\hline Inoculum & 7,28 & 3,19 & 83,81 & 445,2 & 11,9 & 16,19 \\
\hline
\end{tabular}

Table 5. Analysis for Variously Chopped Green Reeds

\begin{tabular}{|l|l|l|l|l|l|l|}
\hline $\begin{array}{l}\text { Chopped } \\
\text { green } \\
\text { reeds }\end{array}$ & $\begin{array}{l}\mathrm{pH} \\
\text { mixed } \\
\text { substrate }\end{array}$ & of $\%$ & $\begin{array}{l}\text { ODM } \\
\%\end{array}$ & Ash \% & DM g & ODM g \\
\hline$-2 \mathrm{~mm}$ & 6,76 & 46,35 & 89,71 & 10,39 & 9,27 & 8,32 \\
\hline$-5 \mathrm{~mm}$ & 6,7 & 56,25 & 90,51 & 9,49 & 11,25 & 10,18 \\
\hline$-7 \mathrm{~mm}$ & 6,83 & 52,08 & 91,12 & 8,88 & 10,42 & 9,49 \\
\hline$-20 \mathrm{~mm}$ & 6,84 & 41,49 & 91,83 & 8,13 & 8,30 & 7,62 \\
\hline Inoculum & 6,86 & 3,12 & 83,92 & 16,08 & 15,6 & 13,09 \\
\hline
\end{tabular}

Comparing analysis of dry and green reeds shows that dry reeds have much more dry and organic dry matter than green reeds.

For green reeds average biogas and methane yield from different chopped green reeds in $1 /$ gODMadd is shown in Figure 2. Dry and green reeds fermentation comparison is shown in Figure 3. Methane yield from green reeds is higher than from dry reeds.

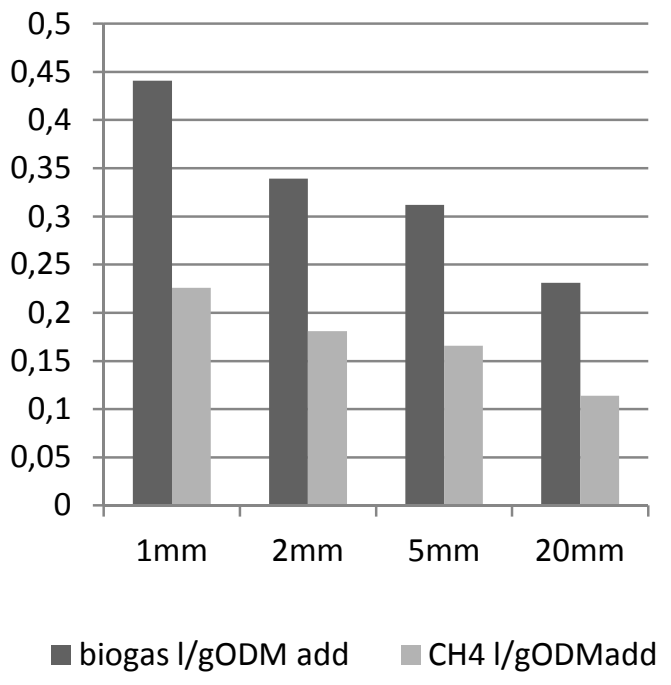

Fig.1 Average biogas and methane yield from digesters with dry reed in $1 / \mathrm{gODMadd}$.

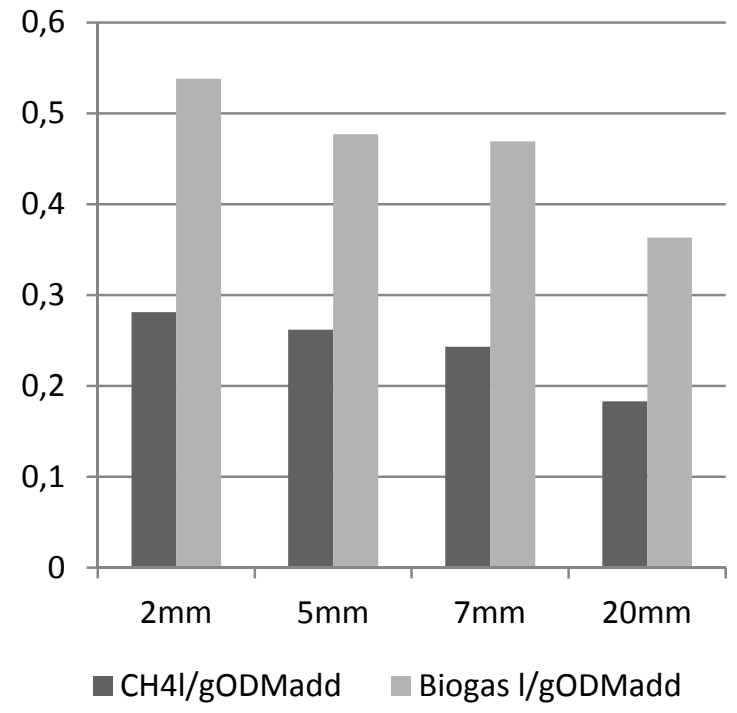

Fig.2 Average biogas and methane yield from different chopped green reeds in 1/gODMadd

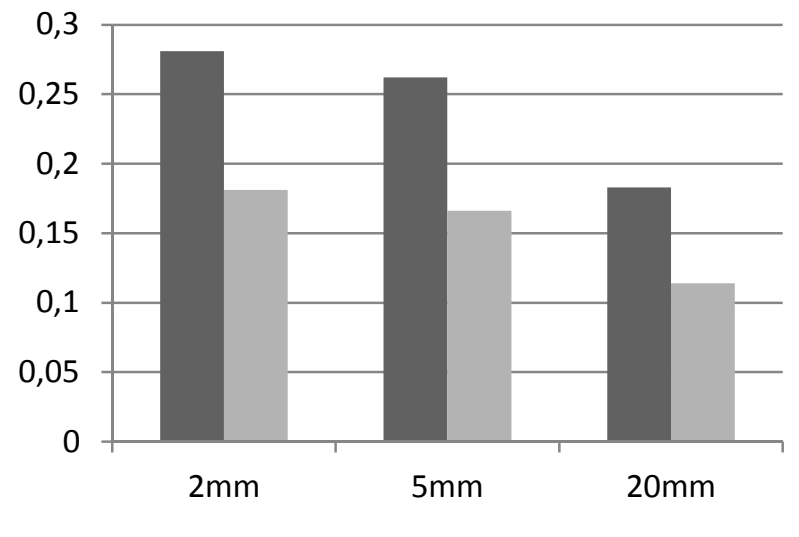

green reed I/gODMadd dry reed I/gODMadd

Fig.3 Dry and green reeds fermentation results comparison 


\section{Conclusions}

1. The Pape lake area reeds can be used as raw materials for biogas production.

2. Reeds chemical analysis shows that powdered dry $(\mathrm{C} / \mathrm{N}=128.3)$ and powdered green $(\mathrm{C} / \mathrm{N}=$ 50.86 ) reeds have an unfavourable $\mathrm{C} / \mathrm{N}$ ratio for anaerobic digestion. Green reeds have much better $\mathrm{C} / \mathrm{N}$ ratio.

3. Reeds have high lignin, cellulose (from 32.45 to $38.29 \%$ ) and hemicelluloses (29.88 to $32.16 \%$ ) content.

4. Dry (winter cut) reeds have a high dry matter $(\mathrm{DM}=87.5$ to 92.65$)$ and organic dry matter

\section{References}

1. Directive 2009/28/EC "on the promotion of the use of energy from renewable sources and amending and subsequently repealing Directives 2001/77/EC and 2003/30/EC", Official Journal of the European Union, L 140, Vol. 52, 2009, p. 148.

2. Adamovičs A., Agapovs J., V. Dubrovskis u.c. Energétisko augu audzēšana (Growing and utilization of energy crops). Rīga: SIA Vides projekti, 2007. 190 lpp.

3. 1. Dr. Claudius da Costa Gomez. Biogas in change. $16^{\text {th }}$ annual meeting of the German Biogas Association. 31-2.02 2007.

4. 2. www.biogas.org

5. Ülo Kask, Aadu Paist, Livia Kask Thermal Engineering Department Tallinn Technical University ,Resources and, Burning Characteristics of Reed and Possibilities to Use it in Energy Production,,., 21st REED SEMINAR - 22nd August 2003
$(\mathrm{ODM}=95.42$ to 95.6$)$ so its contents can be stored without special treatment.

5. The samples of green reeds had relatively high (41.49 to $56.25 \%$ ) dry matter content.

6. Average degrees of bioconversion for different chopped reeds were: $1 \mathrm{~mm}-34-38 \%-2 \mathrm{~mm}, 35$, $39 \% ;-5 \mathrm{~mm}-29 \%$, and $32 \%$ to $14-20 \mathrm{~mm}, 35 \%$, which is small, especially in a few crushed reed at HRT = 51days. This shows that have just broken up quickly digestable substance.

7. Biogas and methane extraction was the largest for the finest crushed reeds $(1 \mathrm{~mm}-8,7251$, 2mm-6, 96 1-5mm-6, 1251 and-20mm-5, 083 l) 